\title{
KARAKTERISTIK ORGANOLEPTIK FILET IKAN PATIN (Pangasionodon hypophthalmus) DARI TIGA LOKASI BUDIDAYA DI KABUPATEN BOGOR
}

\author{
Oleh \\ Tatty Yuniarti, Yuke Eliyani, Alvi Nur Yudistira \\ Dosen Jurusan penyuluhan Perikanan Sekolah Tinggi Perikanan
}

\begin{abstract}
ABSTRAK
Hasil olahan ikan Patin (Pangasionodon hypophthalmus) pada umumnya dipasarkan dalam bentuk fillet, baik beku maupun berbalut tepung roti. Kualitas organoleptik fillet patin ini sangat dipengaruhi oleh berbagai faktor, diantaranya kualitas lingkungan perairan tempat budidaya ikan tersebut, baik fisika maupun kimia. Penelitian ini bertujuan untuk mengidentifikasi karakteristik organoleptik filet ikan patin secara sensori, yang diperoleh dari tiga lokasi budidaya dengan kualitas air yang berbeda di Kabupaten Bogor. Penelitian berlangsung mulai bulan Maret sampai dengan Juni 2013 bertempat di Desa Bantar Kemang, Desa Ciseeng, serta kolam praktek Pasir Jaya Jurusan Penyuluhan Perikanan. Parameter yang diamati terhadap fillet patin meliputi aroma, rasa, penampakan, serta tekstur. Adapun untuk parameter kualtas air terdiri dari suhu, $\mathrm{pH}$, kecerahan, oksigen terlarut, nitrit, amoniak, serta amonium. Hasil penelitian menunjukkan bahwa nilai karakteristik organoleptik illet ikan patin untuk atribut aroma dan rasa dipengaruhi oleh kualitas air.

Kata kunci: ikan patin, filet patin , kualitas air, uji organoleptik

\section{PENDAHULUAN}

\section{Latar belakang}

Ikan patin (Pangasionodon hypophthalmus ) merupakan jenis ikan konsumsi air tawar, yang berprospek cerah, karena memiliki harga jual cukup tinggi. Prospek ini menyebabkan ikan patin mendapat perhatian dan diminati para pengusaha untuk membudidayakannya. Perkembangan produksi budidaya ikan patin menunjukkan kenaikan sangat signifikan. Pada tahun 2006 produksi ikan patin mencapai 31.490 ton pertahun dan pada tahun 2012 mengalami

peningkatan menjadi 651.000 ton pertahun. Kementerian Kelautan dan Perikanan (KKP) terus memacu peningkatan produksi ikan patin dari tahun ke tahun dengan target produksi nasional pada tahun 2013 sebesar 1.107.000 ton (Pusdatin KKP, 2013).

Ikan patin biasanya dipasarkan dalam bentuk filet beku atau disebut sebagai ikan dori. Olahan ikan patin yang cukup dominan adalah filet bertepung roti (breaded). Filet ikan patin yang berwarna putih akan lebih dapat diterima oleh semua pasar dan dengan harga tertinggi. Permintaan akan filet ikan patin berdaging putih meningkat karena tingkat kesegarannya yang tinggi (Warta Perikanan 2009ª).
\end{abstract}


Dalam dunia perdagangan ikan patin dikelompokkan bersadarkan warnanya menjadi 5 kategori yaitu putih bersih (snow white), putih kemerahan (light pink), merah muda (pink), kuning muda (light yellow), dan kuning (yellow) (Warta Perikanan 2009 ${ }^{\mathrm{b}}$ ). Perbedaan warna tersebut terutama disebabkan karena spesies, umur, pakan, dan kualitas lingkungan perairannya (Li et al. 2009).

Untuk memperoleh kualitas daging ikan patin yang pilihan dan unggul sesuai kriteria yang diinginkan konsumen, diperlukan penelitian secara diskriptif terhadap filet ikan patin untuk mengidentifikasi keinginan konsumen dan hubungannya dengan kualitas air lingkungannya. Dengan pengamatan filet ikan patin ini, maka dapat diketahui tingkat penerimaan konsumen ikan patin yang berbeda lingkungannya.

\section{Tujuan}

Tujuan dari penelitian ini adalah untuk mengidentifikasi karakteristik organoleptik filet ikan patin secara sensori yang diperoleh dari tiga lokasi budidaya dengan kualitas air yang berbeda di Kabupaten Bogor.

\section{Waktu dan Tempat Penelitian}

Penelitian berlangsung mulai bulan Maret sampai dengan Juni 2013 bertempat di Desa Bantar Kemang, di desa Ciseeng, dan kolam praktek Jurluhkan Cikaret. Uji organoleptik dilakukan di kampus Jurusan Penyuluhan Perikanan ,sedangkan Untuk pengujian kualitas air dilakukan di Laboratorium STP Pasar Minggu .

\section{Alat dan Bahan}

Alat yang digunakan antara lain pisau, talenan, coolbox, peralatan glass ware untuk pengujian, timbangan, oven, $\mathrm{pH}$ meter. Thermometer, secchi disk, mikroskop. Alat-alat gelas, Timbangan analitik, Erlenmayer, botol polietilen 250 $\mathrm{mL}$, kertassaring whatman $\mathrm{GF} / \mathrm{C}$, labu ukur, pipetvolumetrik, pipet ukur, pipet tetes, desikator,Quality water Cheker YSI 556 NPS, danSpektrofotometer UVVIS Simadzu 1200.

Bahan penelitian untuk uji karakteristik fillet adalah ikan patin yang diperoleh dari tiga (3) lokasi budidaya, yaitu di Desa Bantar Kemang, di desa Ciseeng, dan kolam praktek Jurluhkan Cikaret. Bahan lain adalah scoresheet untuk uji sensori dan bahanbahan kimia untuk uji kualitas air yang terdiri dari Bahan kimia yang digunakan meliputi larutan asam sulfat $\left(\mathrm{H}_{2} \mathrm{SO}_{4}\right)$, larutan kalium antimoniltartrat $\left(\mathrm{K}(\mathrm{SbO}) \mathrm{C}_{4} \mathrm{H}_{4} \mathrm{O}_{6} \cdot 1 / 2 \mathrm{H}_{2} \mathrm{O}\right), \quad$ larutan amonium molibdat $\left(\left(\mathrm{NH}_{4}\right)_{6} \mathrm{Mo}_{7} \mathrm{O}_{24} \cdot 4 \mathrm{H}_{2} \mathrm{O}\right)$, larutan asam askorbat $\left(\mathrm{C}_{6} \mathrm{H}_{8} \mathrm{O}_{6}\right), \mathrm{KH}_{2} \mathrm{PO}_{4}$, Air suling bebas nitrit, Indikator fenolftalen, glass wool, kertas saring bebas nitrit berukuran pori $0,45 \mu \mathrm{m}$, larutan asam sulfanilamida, larutan natrium oksalat $\left(\mathrm{Na}_{2} \mathrm{C}_{2} \mathrm{O}_{4}\right)$, Fenol, Larutan campuran (dicampur $50 \mathrm{~mL}$ larutan $\mathrm{H}_{2} \mathrm{SO}_{4} 5 \mathrm{~N}, 5 \mathrm{~mL}$ Kalium Antimonil tartrat, $15 \mathrm{~mL}$ amoniummolibdat dan 30 $\mathrm{mL}$ asam askorbat), larutanpengoksida (dicampur larutan alkalin sitrat100 mL dengan $25 \quad \mathrm{~mL}$ natrium hipoklorit),natrium nitroprusid, natrium oksida klorida, $\mathrm{NaOH}, \mathrm{MnSO}_{4}, \mathrm{KMnO}_{4}$, $\mathrm{HCl}$ pekat, $\mathrm{CHCl}_{3}, \mathrm{NaNO}_{2}, \quad$ Ferro Ammonium Sulfat (FAS),NED dihidroklorida, larutan standar 
$\mathrm{KNO}_{3}$, larutan induk nitrit $250 \mathrm{mg} / \mathrm{L}$, larutan induknitrat $250 \mathrm{mg} / \mathrm{L}$.

\section{METODA PENELITIAN}

Penelitian dilakukan secara sensory untuk fillet patin dengan berat sampel \pm 100 gram per responden. Pengambilan sampel dilakukan secara grid dan komposit untuk validasi data. Karakteristik ikan patin dari ketiga sumber budidaya tersebut diuji secara organoleptis menggunakan scoresheet dengan 15 panelis semi terlatih dengan metoda uji hedonik. Parameter uji meliputi penampakan, tekstur, aroma, rasa. Untuk atribut rasa, filet patin dikukus terlebih dahulu (Setianingsih,
2012). Pengamatan kualitas air kolam dilakukan selama 2 minggu berturutturut setiap dua hari sekali.

Pengukuran parameter fisik seperti suhu, DO, kecerahan, $\mathrm{pH}$, dilakukan insitu (di lapangan). Penentuan kadar Amonuma (NH4) dan Nitrit $\left(\mathrm{NO}_{2}\right)$ dilakukan dengan metode spektrofotometer. Kadar amonia ditentukan dengan menggunakan tabel hubungan antara $\mathrm{pH}$ dengan suhu ( Boyd, 1990).

\section{HASIL PENELITIAN}

Hasil uji karakteristik sensory terhadap sampel fillet patin secara orgnoleptik, tertera pada Gambar 1.

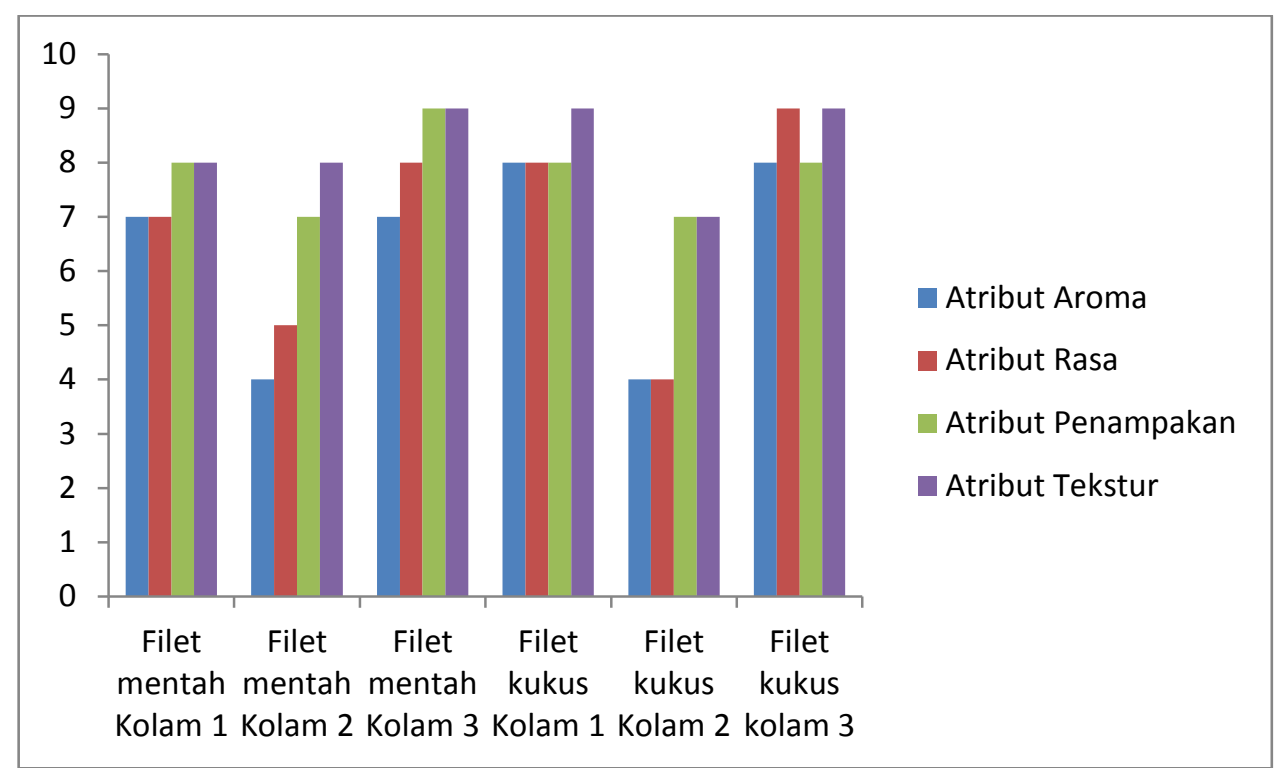

Gambar 1. Hasil Uji Karakteristik Sensory filet patin mentah dan filet patin kukus pada tiga sumber budidaya yang berbeda

Uji organoleptik sensory dilakukan dengan menghitung tingkat kesukaan panelis. Data yang diperoleh menunjukkan bahwa kesukaan panelis terhadap aribut aroma dan rasa pada filet mentah ikan patin yang dibudidayakan pada kolam 2 lebih rendah daripada pada filet dari kolam 1 dan 2. Demikian pula pada filet yang dikukus. Sedangkan hasil uji terhadap atribut tekstur dan penampakan filet ikan patin baik yang mentah dan yang dikukus tidak menunjukkan perbedaan nilai organoleptik pada kolam 1, 2 dan 3.

Rendahnya tingkat kesukaan pada aroma dan rasa filet patin dari kolam ini 
kemungkinan berhubungan dengan kualitas air tempat budidaya ikan patin tersebut. Senyawa kimia yang terbentuk dalam kolam dapat mempengaruhi kualitas filet ikan patin berdasarkan mekanisme difusi melalui makanan (Lalezary et al. 1986). Selain hal tersebut, diduga pada kolam 2 terdapat fitoplankton dari Jenis Blue green algae (Acinetobacter dan Nocardia) sebagai penghasil senyawa geosmin dan methyl iso borneol (MIB) yang dapat memberi aroma musty dan earthy, sehingga menurunkan tingkat penerimaan konsumen (Ho et al 2007).
Tekstur dan penampakan kemungkinan berhubungan dengan kecepatan aliran air budidaya, selain kualitas airnya (Oedjoe et al. 2012). Hasil penelitian Oedjoe et al terhadap ikan Tiger grouper ( Epinephelus fuscoguttatus ) yang dipelihara pada berbagai nilai kecepatan aliran air menunjukkan adanya perbedaan pada nilai kekompakan tekstur daging akibat meningkatnya ukuran serat otot. Hasil histologi terhadap serat otot dan bagian endomysium tertera pada Gambar 2.
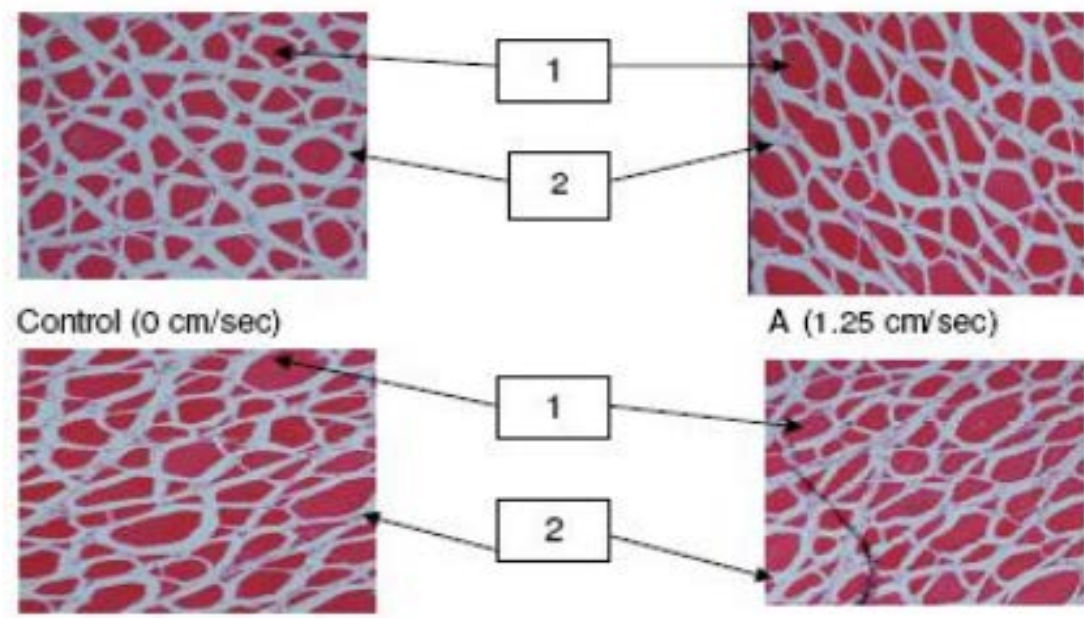

$\mathrm{B}(1.00 \mathrm{~cm} / \mathrm{sec})$

C $(0.75 \mathrm{~cm} / \mathrm{sec})$

Fig. 2. The histology of muscle cross-sectional sections from experiment tanks at $400 \times$ magnification. Number 1 indicates the muscle fibers and the number 2 points to endomy sium.

Hasil uji kualitas air terhadap parameter suhu, $\mathrm{pH}$, kecerahan, DO, $\mathrm{NH}_{4}{ }^{+}$serta $\mathrm{NO}_{2}$ dapat dilihat pada Tabel 1 dan 2.

Tabel 1. Hasil uji kimia dan fiska kualitas air 3 kolam yang berbeda

\begin{tabular}{ccccc}
\hline Parameter & Satuan & Kolam 1 & Kolam 2 & Kolam 3 \\
\hline Suhu & ${ }^{\circ} \mathrm{C}$ & 24 & 26 & 24. \\
$\mathrm{pH}$ & - & 7,2 & 7,6 & 7,2 \\
Kecerahan & $\mathrm{Cm}$ & 25 & 17 & 27 \\
$\mathrm{DO}$ & $\mathrm{mg} / \mathrm{L}$ & 4,79 & 6,38 & 5,58 \\
$\mathrm{NH}_{4}^{+}$ & $\mathrm{mg} / \mathrm{L}$ & 0,006 & 0,008 & 0,003 \\
$\mathrm{NO}_{2}$ & $\mathrm{mg} / \mathrm{L}$ & 0,002 & 0,005 & 0,001 \\
\hline
\end{tabular}

Sumber : data diolah (2013) 
Adapun untuk penentuan nilai amonia $\left(\mathrm{NH}_{3}-\mathrm{N}\right)$ mengacu pada Boyd 1990 , dengan memperhitungkan korelasi antara nilai $\mathrm{pH}$ dengan suhu air. Nilai minimal $\mathrm{pH}$ serta suhu air yang tertera pada tabel ini masing-masing sebesar 7,0 serta $24^{\circ} \mathrm{C}$, sehingga data yang pada Tabel 1 dapat digunakan.

Tabel 2. Proporsi ammonia dari total ammonia ( $\mathrm{ppm}$ ) berdasarkan suhu dan $\mathrm{pH}$ air

\begin{tabular}{|c|c|c|c|c|c|}
\hline \multirow{2}{*}{$\mathbf{P H}$} & \multicolumn{5}{|c|}{ SUHU AIR ( O C 0 } \\
\cline { 2 - 6 } & $\mathbf{2 4}$ & $\mathbf{2 6}$ & $\mathbf{2 8}$ & $\mathbf{3 0}$ & $\mathbf{3}$ \\
\hline 7,0 & 0,005 & 0,006 & 0,007 & 0,008 & 0,009 \\
\hline 7,2 & 0,008 & 0,010 & 0,011 & 0,013 & 0,015 \\
\hline 7,4 & 0,013 & 0,015 & 0,018 & 0,020 & 0,023 \\
\hline 7,6 & 0,021 & 0,024 & 0,028 & 0,031 & 0,036 \\
\hline 7,8 & 0,033 & 0,038 & 0,043 & 0,049 & 0,056 \\
\hline 8,0 & 0,051 & 0,058 & 0,066 & 0,075 & 0,085 \\
\hline 8,2 & 0,078 & 0,089 & 0,101 & 0,114 & 0,129 \\
\hline 8,4 & 0,119 & 0,134 & 0,151 & 0,170 & 0,190 \\
\hline 8,6 & 0,176 & 0,197 & 0,220 & 0,245 & 0,271 \\
\hline 8,8 & 0,253 & 0,281 & 0,309 & 0,340 & 0,371 \\
\hline 9,0 & 0,349 & 0,382 & 0,415 & 0,449 & 0,483 \\
\hline 9,2 & 0,460 & 0,495 & 0,530 & 0,564 & 0,597 \\
\hline 9,4 & 0,574 & 0,608 & 0,641 & 0,672 & 0,701 \\
\hline 9,6 & 0,661 & 0,711 & 0,739 & 0,762 & 0,788 \\
\hline
\end{tabular}

Sumber : Boyd (1990)

Dari hasil pengujian kualitas air, kolam 1 dan 3 menunjukkan data kualitas air yang hampr sama nilainya, baik parameter fisika dan kimia. Data ini juga selaras dengan data hasil uji organoleptik. Data yang berbeda diperlihatkan pada kualitas air kolam 2. Data yang sangat berbeda terlihat pada parameter kecerahan, dimana kecerahan kolam 2 lebih rendah dibandingkan kolam 1 dan 3, menunjukkan terdapat partikel-partikel yang mengganggu penetrasi sinar matahari ke bagian bawah kolam. Partikel partikel tersebut dapat berupa plankon dan suspensi lumpur atau kotoran padat lain (Jhon et al. 1997). Sehingga akan mempengaruhi komposisi atau kualitas kimia air, hal ini terlihat pula pada parameter $\mathrm{NO}_{2}$ dan $\mathrm{NH}_{4}$ pada kolam 2.
Ammonia dalam perairan berada dalam bentuk molekul (NH3-N) serta ion $(\mathrm{NH} 4+)$ yang konsentrasinya sangat dipengaruhi oleh suhu dan $\mathrm{pH}$. Air dengan $\mathrm{pH}$ rendah biasanya didominasi oleh $\mathrm{NH} 4+$, sedangkan pada $\mathrm{pH}$ tinggi akan didominasi oleh NH3-N. Berdasarkan tabel 1 dan 2 diatas, nila NH3-N di kolam 1 dan 3 adalah 0,008 ppm, sedangkan untuk kolam 2 sebesar $0,024 \mathrm{ppm}$. Nilai-nilai ini masih berada dalam kisaran ammonia yang dapat ditoleransi oleh ikan air tawar ( Boyd, 1990).

Fiksasi gas nitrogen secara langsung dapat dilakukan oleh beberapa jenis algae Cyanophita (blue green algae) dan bakteri (Effendi, 2003). Keberadaan Blue green algae diduga dapat ilihat dari besaran nilai $\mathrm{NO}_{2}, \mathrm{NH}_{3}$ $\mathrm{N}$ serta $\mathrm{NH}_{4}$ di perairan. Berdasarkan 
tabel 1 dan 2 terlihat bahwa nilai ketiga parameter nitrogen tersebut pada kolam 2 lebih besar kolam 1 dan 3, sehingga diduga jumlah blue green algae di kolam 2 lebih banyak dibanding kolam 1 dan 3 . Hal inilah yang diduga menyebabkan adanya aroma lumpur dari fillet kolam 1, sehingga timbul perbedaan dari hasil uji karakteristik aroma ( Gambar 1.).

Nilai $\mathrm{NH}_{4}$ dan $\mathrm{NO}_{2}$ berhubungan dengan akumulasi komponen organik dalam kolam. Komponen organik dalam kolam ini berhubungan dengan hasil reaksi biokimia yang terjadi di dalam air kolam, seperti reaksi pembusukan, reaksi fermentasi dan reaksi biokimia lain. Senyawa Amonia ini,akan meningkatkan pertumbuhan dan kepadatan fitoplankton. Kepadatan fitoplankton yang tinggi menimbulkan peristiwa ledakan populasi ("blooming"),yang diikuti oleh kematian masal ("die off") fitoplankton. Peristiwa ledakan populasi dan kematian masal fitoplankton akan memperburuk kualitas air tambak, sehingga mempengaruhi rasa dan aroma ikan.

Kadar nitrit $\left(\mathrm{NO}_{2}\right)$ pada kolam 2 berkaitan erat dengan bahan organik yang ada pada zona ini (baik yang mengandung unsur nitrogen maupun tidak). Diantaranya penguraian bahan organik oleh mikroorganis mememerlukan oksigen dalam jumlah yang banyak. Oksigen tersebut berasal dari oksigen bebas $\left(\mathrm{O}_{2}\right)$, namun bila oksigen tersebut tidak cukup maka oksigen tersebut diambil dari senyawa nitrat yang pada akhirnya senyawa nitrat berubah menjadi senyawa nitrit (Hutagalung dan Razak, 1997)..

Nilai Oksigen terlarut pada ketiga kolam bervariasi. Kolam 1 mempunyai nilai DO yang paling rendah yaitu 4,79 ppm, kolam 2 sebesar 6,38 ppm, serta kolam 3 sebesar 5,58 ppm. Nilai DO di ketiga kolam masih memenuhi peryaratan jumlah oksigen terlarut untuk budidaya perikanan adalah lebih dari 3 mg/L (SNI :7471.5 : 2009). Sumber oksigen terlarut dapat berasal dari difusi oksigen yang terdapat di atmosfer (sekitar 35\%) dan aktifitas fotosintesa oleh tumbuhan air dan fitoplankton ( Effendi, 2003). Difusi oksigen dari atmosfer ke dalam air dapat terjadi secara langsung pada kondisi air diam (stagnan), maupun kondisi agitasi (pergolakan massa air akibat adanya gelombang). Pada umumnya difusi oksigen dari atmosfer ke perairan berlangsung relatif lambat meskipun terjadi agitasi, sehingga sumber utama oksigen di perairan adalah fotosintesa. Hal inilah yang diduga menyebabkan nilai oksigen terlarut di kolam $2(6,38$ ppm) lebih tinggi dari kolam 1 dan 3 ( masing-masing sebesar 4,79 ppm dan $5,58 \mathrm{ppm})$. Kondisi ini terkait dengan nilai kecerahan di kolam 2 lebih rendah dibandingkan kolam 1 dan 3 , yang diduga dipacu oleh kepadatan populasi fitoplankton di kolam 2 yang diperkirakan lebih padat dibandingkan dengan kolam 1 dan 3.

\section{KESIMPULAN}

Karakteristik organoleptik filet ikan patin untuk atribut aroma dan rasa dipengaruhi oleh kualitas air, terutama parameter nitrit, amoniak serta amonium. Pengaplikasian di lapangan untuk mengatasi hal ini adalah dengan pengelolaan kualitas media budidaya diantaranya mengatur volume pemasukan air kedalam kolam untuk 
meminimalkan nilai nitrogen oranik dan an organik.

\section{DAFTAR PUSTAKA}

Boyd, CE. 1990. Water Quality in Ponds for Aquaculture. Birmingham Publishing Co.

Effendi Hefni. 2003. Telaah Kualitas Air Bagi Pengelolaan Sumber Daya dan Lingkungan Perairan. Kanisius. Yogyakarta.

Ho L, D Hoefel, F Bock, CP. Saint, G Newcombe. 2007. Biodegradation rates of 2-methylisoborneol (MIB) and geosmin through sand filters and in bioreactors. Chemosphere 66 (2007) 2210-2218.

Hutagalung, Horas dan Abdul Rozak.1997. Metode Analisis Air Laut, Sedimendan Biota. Buku Kedua. Puslitbang OseanologiLIPI. Jakarta

John J. Cullen, Aurea M. Ciotti, Richard F. Davis, and Marlon R. Lewis. 1997. Optical detection and assessment of algal blooms. Lmnol. Oceonogr 42(5, part 2), pg 1223-1229.

Lalezary, S., Pirbazari, M., McGuire, M.J., 1986. Oxidation of five earthy-musty taste and odor compounds. J. Am. Water Works Ass. 78, 62-69.
Li M, Robinson M, Oberle D. 2009. Yellow Pigments in Catfish evaluated. The Catfish Journal, February 2009.p 11. 14.

Oedjoe MDR, E. Suprayitno, Aulanni'am, E. Y.Herawati. 2012. Effects of Water Flow Speed on Muscle Histology and Survival Rate in Improving Tiger Grouper Hatchlings Quality. International Journal of Basic \& Applied Sciences IJBAS-IJENS Vol:12 No:06.

Pusdatin KKP. 2013. Siaran pers KKP: TARGETKAN PRODUKSI PATIN 1,1 JUTA TON Error! Hyperlink reference not valid.. id/index.php /arsip/c/ 8912/KKP TARGETKAN- PRODUKSIPATIN-11-JUTATON/?category_id $=34 \mathrm{KKP}$ diunduh 9 April 2013.

SNI 7471.5 : 2009. Ikan patin jambal (Pangasius djambal) - Bagian 5: Produksi Kelas Pembesaran di Kolam.

Sularto. 2008. Ikan Patin Pasupati sebagai Komoditas andalan. Makalah disampaikan pada Diseminasi Hasil Riset Ikan Patin Jambi, 30 Oktober 2008.

Warta Perikanan. 2009.Tahun 2009 Industri Patin Vietnam Berkembang. Warta Perikanan (67): 10-11. 